\title{
Hardness determination of EBiD-layers containing tungsten and cobalt
}

\author{
T. Wich, T. Luttermann \& I. Mircea \\ Division Microrobotics and Control Engineering, \\ University of Oldenburg, Germany
}

\begin{abstract}
Electron Beam induced Deposition (EBiD) is a promising process technology for nano-structuring and -prototyping inside a scanning electron microscope (SEM). Firstly, the EBiD-process used for layer deposition is described. We have performed nanoindentation experiments on EBiD-layers with the purpose of determining their hardness. A special setup for nanoindentation inside the SEM is described. Before performing tests on EBiD-layers, calibration measurements on fused silica and sapphire were necessary. Hardness of the silicon wafer substrate and of the EBiD-layers has been also determined. The layers were small quadrates, with dimensions in the range of $20 \times 20 \mu \mathrm{m}^{2}$, with a thickness varying between 93 and $2256 \mathrm{~nm}$. Nanoindentation tests on the deposited layers revealed values between 7.1 and $10.0 \mathrm{GPa}$ for tungsten containing deposits and between 3.4 and 3.5 for cobalt containing deposits depending on the metal-content.
\end{abstract}

Keywords: Electron Beam induced Deposition, hardness, nanoindentation.

\section{Introduction}

The effect of Electron Beam induced Deposition (EBiD) was first observed in 1933, by R.L. Stewart. At that time he noted that on surfaces under electron bombardment thin insulating films have been observed [14]. These insulating films have been regarded as an inevitable effect in evacuated electron tubes. Ennos et al. have conducted tests with different seals, grease materials, and oil for vacuum pumps, for determining their influence on the contamination thickness [6]. Based on the results of these tests, Christy developed in 1960 a theoretical model which can explain the deposition of polymer films under electron bombardment [2]. Later, these deposits have always been seen as a 
possible deposition technology for manufacturing nanometer scale resists [1] or conducting lines on the nanometer scale [7]. However, about the mechanical properties of such deposits, only few data are available. They are of great interest, because, in the last years, many mechanical devices on the nanometer scale are developed using this technology e.g. bonding of nanowires $[5,18]$ or formation of AFM-super-tips [11]. Only few material data have been reported i.e. the elasticity modulus of deposits $[9,15]$ or their tensile or bending strength $[9,15]$. The elasticity modulus has been determined by means of the bending test method. However, hardness of layer deposits manufactured by the EBiD process has only been determined for a paraffin precursor, resulting in hydrogenated amorphous carbon deposits [5], by means of the nanoindentation test method.

After this introduction, in section 2 the EBiD-process is shortly explained. In section 3 the testing procedure is described, containing the description of the nanoindentation set-up, the necessary calibration of this set-up, the nanoindentation tests on EBiD-layers, the AFM measurements of the thickness of the layers, and the EDX analysis of their chemical content. In section 4, the results from these experiments on layer containing tungsten-hexacarbonyl $\left(\mathrm{W}(\mathrm{CO})_{6}\right)$ and di-cobalt-octacarbonyl $\left(\mathrm{Co}_{2}(\mathrm{CO})_{8}\right)$ precursors are shown and discussed, as well as the observed futures of the imprints after nanoindentation tests are described and discussed. Finally, in section 5, conclusions have been drawn.

\section{Processing of specimens by EBiD}

The indentation experiments in this work have been conducted on very thin layers, deposited from metallo-organic precursors by EBiD inside a scanning electron microscope (SEM).

The substrate was a silicon wafer with a shape of a square and dimensions of $5 \times 5 \mathrm{~mm}^{2}$. While scanning the substrate in the simple viewing mode of the SEM in a range of approx. $20 \times 20 \mu \mathrm{m}^{2}$, the evaporated precursor flux is directed to the deposition area using a capillary. A side view of the substrate surface with precursor flow area, scan area of the electron beam and the resulting deposition is shown in figure 1. The precursor molecules adsorb on the substrate surface and are decomposed into volatile and non-volatile fragments. The volatile fragments are pumped by the SEM's vacuum system whereas the non-volatile parts form a solid layer in the scanned area on the substrate. In the literature [13] it has been shown that the secondary electrons generated by the primary electron beam when hitting the substrate activate the dissociation process. The influence of the heat is not clear and is still discussed in literature [3, 8].

The tested layers in this work were deposited from the metallo-organic precursors $\mathrm{W}(\mathrm{CO})_{6}$ (tungsten hexacarbonyl, CAS-Nr. 14040-11-0) and $\mathrm{Co}_{2}(\mathrm{CO})_{8}$ (dicobalt octacarbonyl, CAS-Nr. 10210-68-1). In both cases, the exposure to the electrons leads to separation of volatile fragments (e.g. $\mathrm{CO}$ and $\mathrm{CO}_{2}$ ); the resulting solid deposition consists of tungsten or cobalt, respectively and remaining carbon and oxygen $[4,17]$. 


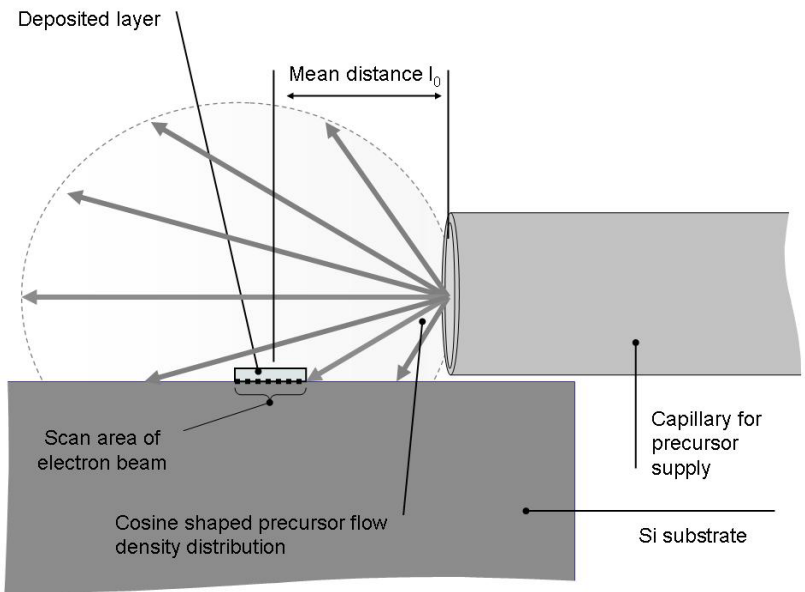

Figure 1: $\quad$ Side view of the substrate surface with precursor flow area, scan area of the electron beam and resulting deposition.

Table 1: Deposition parameters and precursors for the prepared layers. Testing procedure.

\begin{tabular}{|c|c|c|c|c|}
\hline Specimen & Precursor & $\begin{array}{c}\text { Layer } \\
\text { dimensions, } \\
{[\mu \mathrm{m} \times \mu \mathrm{m}]}\end{array}$ & $\begin{array}{c}\text { Beam } \\
\text { current, [nA] }\end{array}$ & $\begin{array}{c}\text { Deposition } \\
\text { time, } \\
{[\text { hours }]}\end{array}$ \\
\hline $\mathrm{Co} \# 1$ & $\mathrm{Co}_{2}(\mathrm{CO})_{8}$ & $25 \times 25$ & 6 & 3 \\
\hline $\mathrm{Co} \# 2$ & $\mathrm{Co}_{2}(\mathrm{CO})_{8}$ & $25 \times 25$ & 6 & 5 \\
\hline $\mathrm{Co} \# 3$ & $\mathrm{Co}_{2}(\mathrm{CO})_{8}$ & $25 \times 25$ & 0.5 & 7 \\
\hline $\mathrm{W} \# 1$ & $W(\mathrm{CO})_{6}$ & $30 \times 30$ & 6 & 5.5 \\
\hline $\mathrm{W} \# 2$ & $W(C O)_{6}$ & $20 \times 20$ & 6 & 5.5 \\
\hline$W \# 3$ & $W(C O)_{6}$ & $25 \times 25$ & 6 & 17 \\
\hline
\end{tabular}

The principal parameters of the deposition process of the layers have been the following: an acceleration voltage of the electron beam of $20 \mathrm{kV}$ and a beam current of $6 \mathrm{nA}$, excepting the third Co-deposition (see table 1).

\section{Hardness determination by nanoindentation}

\subsection{Indentation set-up}

Because of the small dimension of the EBiD layers, for determining their hardness, it was necessary to build up a specialized set-up for nanoindentation inside the SEM. The main reason was the small dimension of the layer deposits i.e. width and length were in the range of approx. $20 \mu \mathrm{m}$. The setup inside the SEM simplified the positioning of the indentation tip on the deposited layer. 
Figure 2 shows the nanoindentation setup inside the SEM. The main advantage of this setup is its compactness. The whole setup has been fixed on the 5-axis stage of the SEM. The indentation setup consists of the part holding the specimen and the indentation tip with sensors for force (load cell) and displacement measurements (piezo stack with strain gages).

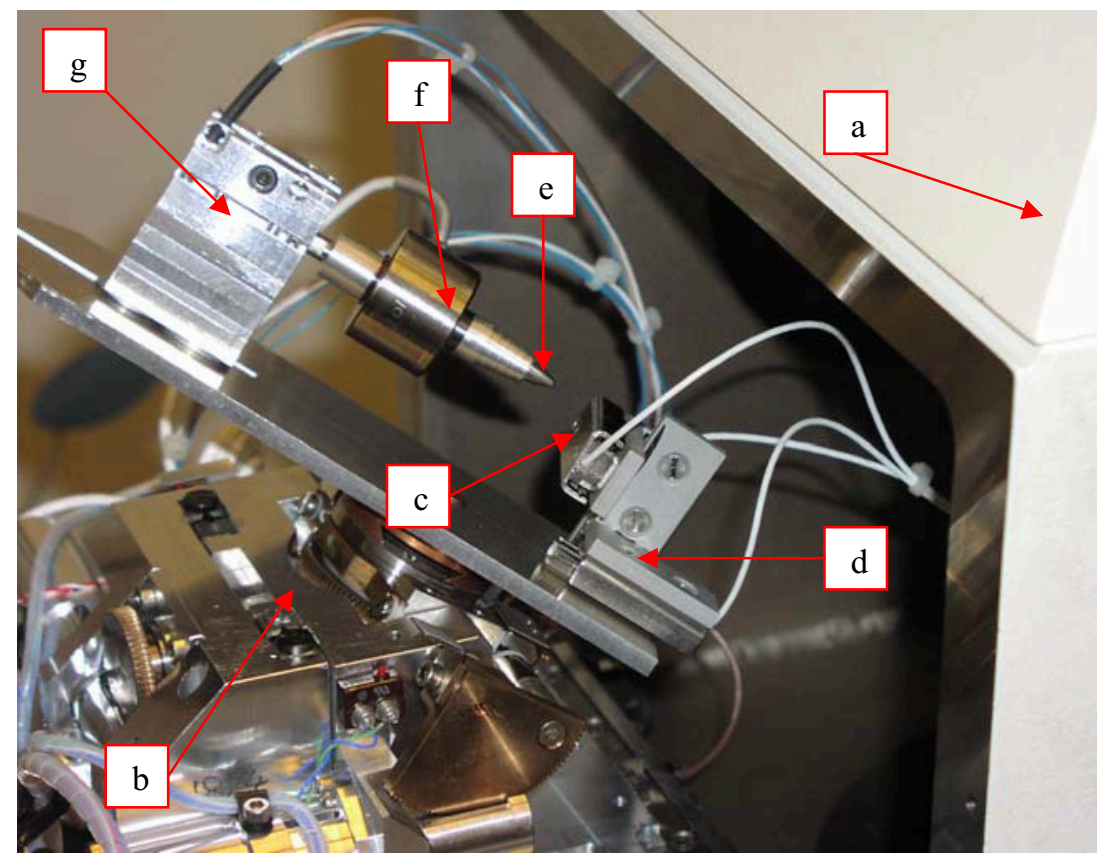

Figure 2: Nanoindentation setup inside the SEM: (a) SEM's vacuum chamber; (b) 5-axis stage; (c) specimen holder; (d) three Cartesian drives; (f) load cell; (g) piezo stack actuator.

The specimen holder is mounted on one of the three Cartesian linear drives (SmarAct GmbH, Germany), which utilize the slip-stick driving principle; the minimum slip-stick step size is approximately $20 \mathrm{~nm}$. These drives are used for the coarse positioning of the specimen beneath the indenter. A distance below $1 \mu \mathrm{m}$ is required. The used indenter was a diamond Berkovich tip. For penetrating the EBiD layers, a piezo stack actuator has been used. It is equipped with integrated strain gages which allow the measurement of the deflection of the indenter. The differential voltage of the Wheatstone bridge built up by the strain gages of the piezo actuator has been evaluated by using a bridge amplifier. The deflection of the piezo stack and the corresponding signal of the bridge amplifier have been calibrated using a laser interferometer, resulting in a linear behaviour. For measuring the force applied on the specimen during indentation, a highly sensitive load cell (Honeywell) has been mounted between the piezo stack actuator and the indentation tip. The load cell has been calibrated by using small 
precision weights. It has also a linear behaviour. The control and the data acquisition have been managed with the help of a LabVIEW-program. This program allows performing a cycle with a defined indentation depth (displacement controlled nanoindentation) and holding time.

\subsection{Calibration tests of the nanoindentation set-up}

After the work of Oliver and Pharr [12], for a precise determination of mechanical properties of a bulk material or of a coating system (Young's modulus and hardness), two calibrations are necessary: the calibration of the area function of the indenter and the calibration of the stiffness of the nanoindentation device. For this purpose, nanoindentation tests with minimum 10 different maximum loads on two different reference specimens e.g. fused silica and sapphire with a relative high Young modulus must be performed. Fused silica has a Young's modulus of $72 \mathrm{GPa}$, sapphire has a Young's modulus of $420 \mathrm{GPa}$. Moreover, to assure a good statistic, 5 tests with the same maximum indentation load have been conducted. The maximum measured indentation depth was $1 \mu \mathrm{m}$. A small quadrate of fused silica $\left(8 \times 8 \mathrm{~mm}^{2}\right.$, thickness $\left.3 \mathrm{~mm}\right)$ and a small disc of sapphire (diameter $8 \mathrm{~mm}$, thickness $3 \mathrm{~mm}$ ) have been the reference specimens. They are very well polished on both sides, so that the roughness of their surfaces is very low ( $\mathrm{RMS}<1 \div 2 \mathrm{~nm}$ ). The calibration tests have been performed with the set-up described above. The reference specimens have been glued on a small holding plate; then this plate was screwed on the positioning table. A Berkovich indenter (Producer Synton MDP, Switzerland) was used for performing all calibrations. The data of the tests have been processed with a special software (Indent Analyser, ASMEC Germany). The software can calculate the area function of the indenter and the stiffness of the nanoindentation set-up, by processing the recorded data. Unfortunately, because of the precision limits of our used force and displacement sensors in the range of small depths, we have no sufficiently good calibration data on fused silica specimen. Having only the area function of the indenter, we have only determined the hardness of the tested materials. We have verified the obtained area function by performing tests on Si substrate. The calculated values of the Si hardness are in accordance with results in literature.

\subsection{Indentation tests}

The specimens were investigated just after the processing of the coating. The maximum measured indentation depth was $1 \mu \mathrm{m}$. Knowing the thickness of the layers (see section 3.4), we have tried to keep an approximately ratio of $1 / 10$ between the indention depth and the coating thickness [19], which was not always possible. It is especially critical for very thin layers (e.g. $<100 \mathrm{~nm}$ ). The used load-time sequence was the same as Oliver and Pharr [12] have used in their work: loading, then a loading time of 100s and finally unloading, see fig.3.

For calculating hardness, the data have been processed with the same software as that used for the calibration tests. 


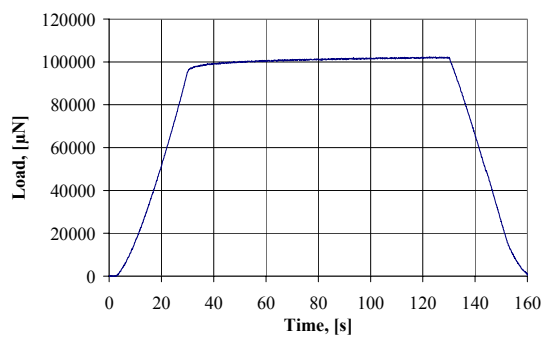

Figure 3: $\quad$ Load-time diagram of a test on Si substrate.

\subsection{Measurement of the thickness and determination of the chemical composition of the layers}

For measuring the thickness of the EBiD-layers, the specimens have been examined with an Atomic Force Microscope (AFM) in contact mode. The results of these measurements can be seen in table 2. However, it was not possible to measure the thickness of all deposits. The samples Co \#1 and Co \#2 were samples which delaminated during indentation. Thus AFM measurements have damaged the samples. As these samples were very thick compared to the others, it was possible to measure the thickness by tilted imaging in the SEM. Thus, the error should be bigger than indicated through the standard deviation of the data shown in table 2. Sample Co \#4 could not be measured with the AFM, because a relative large area of the deposited layer spalled up and the chips were spread over the deposition area. This has led to not exact AFM measurements because of the fouling of the tip.

Each deposited layer was examined for determining its material composition, by using X-ray analysis after the nanoindentation tests. The specimen Co \#3 has been deposited with a lower beam current, resulting in a lower Co content. Because the power irradiated on the deposition spot was higher for high beam currents, it leads to heating effects resulting in deposits with a higher metal content. This effect has been also reported in literature [16].

Table 2: Thickness measurements and chemical composition of the deposited layers with the standard deviation of the measurements.

\begin{tabular}{|c|c|c|c|c|c|c|}
\hline $\begin{array}{c}\text { Speci- } \\
\text { men }\end{array}$ & $\begin{array}{c}\text { Thickness } \\
{[\mathrm{nm}]}\end{array}$ & $\begin{array}{c}\text { Meas. } \\
\text { with }\end{array}$ & $\begin{array}{c}\mathrm{atm} \% \\
\text { C }\end{array}$ & $\begin{array}{c}\mathrm{atm} \% \\
\text { O }\end{array}$ & $\begin{array}{c}\mathrm{atm} \% \\
\text { Co }\end{array}$ & $\begin{array}{c}\mathrm{atm} \% \\
\text { W }\end{array}$ \\
\hline Co \#1 & $\sim 1436 \pm 34$ & SEM & $42 \pm 7$ & $10 \pm 1$ & $48 \pm 11$ & - \\
\hline Co \#2 & $\sim 2256 \pm 90$ & SEM & $47 \pm 3$ & $9 \pm 0$ & $44 \pm 2$ & - \\
\hline Co \#3 & $93 \pm 45$ & AFM & $52 \pm 3$ & $13 \pm 1$ & $35 \pm 2$ & - \\
\hline W \#1 & $353 \pm 76$ & AFM & $42 \pm 5$ & $11 \pm 1$ & - & $47 \pm 8$ \\
\hline W \#2 & $116 \pm 114$ & AFM & $39 \pm 3$ & $10 \pm 1$ & - & $50 \pm 4$ \\
\hline W \#3 & $469 \pm 59$ & AFM & $29 \pm 4$ & $8 \pm 1$ & - & $62 \pm 4$ \\
\hline
\end{tabular}




\section{Results and discussion}

\subsection{Hardness of EBiD-layers}

The results of the hardness measurements for the different EBiD deposits, for $\mathrm{Si}$ substrate and for carbon deposits from literature [5], are shown in table 3.

The hardness of Si substrate of $12.81 \mathrm{GPa}$ agrees well with a value from literature e.g. $12.1 \mathrm{GPa}[10]$. The hardness of $\mathrm{W}(\mathrm{CO})_{6}$ coatings is bigger than the hardness of the $\mathrm{Co}_{2}(\mathrm{CO})_{8}$ coatings. There are also small differences between the hardness of coatings deposited in the same composition. The fact that the hardness of the $\mathrm{W}(\mathrm{CO})_{6}$ is bigger than the hardness of the $\mathrm{Co}_{2}(\mathrm{CO})_{8}$ coatings is also confirmed by the difference in the slope of the loading stage of the nanoindentation tests, see figure 4.

Table 3: $\quad$ Measured hardness of each deposit and values from literature for Si and carbon.

\begin{tabular}{|c|c|c|}
\hline Specimen & $\begin{array}{c}\text { Calculated hardness, } \\
{[\mathrm{GPa}]}\end{array}$ & $\begin{array}{c}\text { Hardness values } \\
\text { found in Literature } \\
{[\mathrm{GPa}]}\end{array}$ \\
\hline $\mathrm{Si}$ (substrate) & 12.81 & $12.1[10]$ \\
\hline Co \#1 & $3.51 \pm 0.13$ & \\
\hline $\mathrm{Co} \# 2$ & $3.56 \pm 1.75$ & \\
\hline $\mathrm{Co} \# 3$ & $3.40 \pm 1.81$ & \\
\hline $\mathrm{W} \# 1$ & $10.00 \pm 0.55$ & \\
\hline $\mathrm{W} \# 2$ & $7.16 \pm 0.29$ & \\
\hline W\#3 & $7.2 \pm 0.20$ & $3.6-4.4[5]$ \\
\hline Carbon & & \\
\hline
\end{tabular}

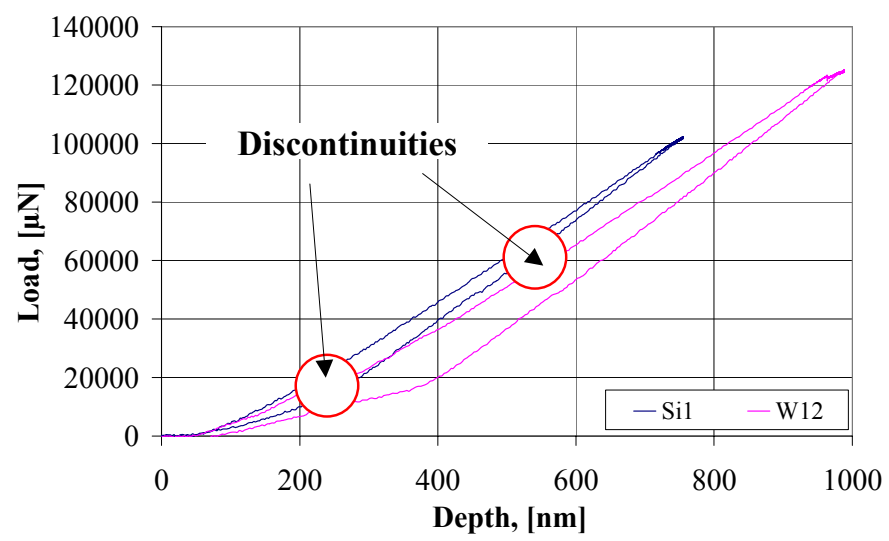

Figure 4: Different slopes of the loading stage of nanoindentation curves for materials with different hardness.

For the material with a bigger hardness, namely $\mathrm{Si}$, its load-depth diagram has a steeper slope for the loading stage of the test than the corresponding slope of 
diagram of the test on $\mathrm{W}(\mathrm{CO})_{6}$ coating. It can be concluded that, for reaching the same indentation depth as in the case of the $\mathrm{W}(\mathrm{CO})_{6}$ coating (smaller hardness), a higher indentation force was necessary for the case of $\mathrm{Si}$.

\subsection{Evaluation of the imprints after nanoindentation tests on the different EBiD layers}

If the SEM photos of the imprints on the layers deposited from $\mathrm{W}(\mathrm{CO})_{6}$ and of the imprints on the layers from $\mathrm{Co}_{2}(\mathrm{CO})_{8}$ (see figure below) are compared, there are some differences between their fracture behaviours under indentation load to notice.

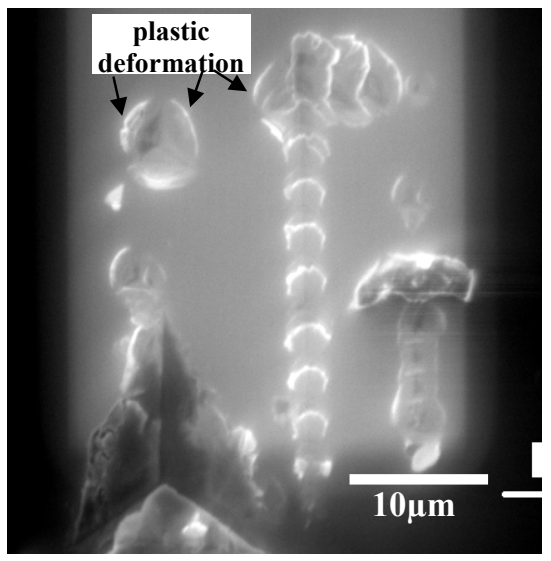

$\mathbf{a}$

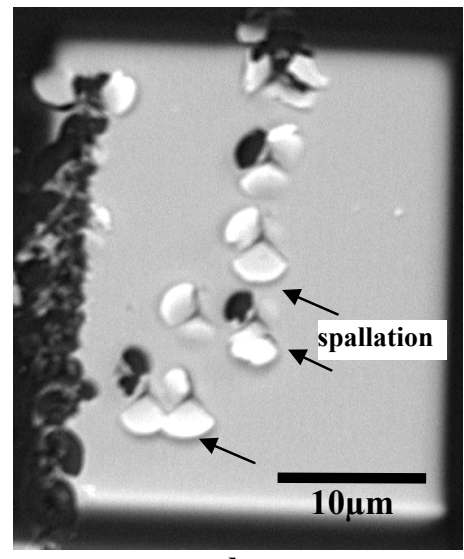

b

Figure 5: Overview of imprints in the coating after nanoindentation tests (a) on a $\mathrm{Co}_{2}(\mathrm{CO})_{8}$; (b) on a $\mathrm{W}(\mathrm{CO})_{6}$ deposit (right picture).

The harder layers (W) shows an accentuate spallation; many chips around the imprint area can be seen. This fracture behaviour is characteristically for a brittle material. This effect has also been observed during bending tests on pin-like deposits made from tungsten-hexacarbonyl; elastic deformation until brittle breaking of the pins has been observed [15]. In contrast, the imprints areas on the layers containing $\mathrm{Co}$ show accentuate plastic deformation which is characteristically for a ductile material. The brittle fracture of the layers containing $\mathrm{W}$ can be also associated with discontinuities observed during the loading stage of the nanoindentation tests (see figure 4). Brittle fracture implies crack propagation during loading; in this way, a part of the total energy dissipated in the material system is consumed for the crack propagation; therefore such discontinuities can occur.

\subsection{Discussion}

Bigger hardness of $\mathrm{W}(\mathrm{CO})_{6}$ layers can be explained by taking into consideration good mechanical properties of $\mathrm{W}$. The small differences between the hardness of the $\mathrm{W}(\mathrm{CO})_{6}$ layers can be partially explained by the small difference in $\mathrm{W}$ atm.\% 
and additionally by the influence of the hardness of the $\mathrm{Si}$ substrate for the case of thinner layers. For the $\mathrm{Co}_{2}(\mathrm{CO})_{8}$ layers, the specimens $\mathrm{Co} \# 1$ and $\mathrm{Co} \# 2$ have almost the same hardness i.e. 3.51GPa for specimen Co \#1 in comparison with $3.56 \mathrm{GPa}$ for specimen Co\#2. It can by probably explained by an almost equal Co atm.\% (48\% respectively 44\%). The specimen C0 \#3 has a smaller Co atm. $\%(35 \%)$ and consequently its hardness is slightly smaller, of $3.4 \mathrm{GPa}$. For this difference in Co atm.\%, a bigger difference in hardness could be probably expected. We have to keep in mind that the thickness of specimen Co \#3 was with $93 \mathrm{~nm}$ by far the thinnest for this chemical composition. Therefore, in this case the influence of the hardness of the Si substrate was bigger.

\section{Conclusion}

In this work, hardness of EBiD deposited layers with thicknesses ranging from $90 \mathrm{~nm}$ to $2200 \mathrm{~nm}$ has been determined by means of the nanoindentation test method. For this purpose, a self built nanoindentation set-up has been used. The big advantage of this set-up is that, because of its compactness, it can be used inside of a SEM. In this way, the indenter can be easily positioned on the desired area for testing. For the $\mathrm{EBiD}$ deposits, precursors tungsten-hexacarbonyl $\left(\mathrm{W}(\mathrm{CO})_{6}\right)$ and di-cobalt-octacarbonyl $\left(\mathrm{Co}_{2}(\mathrm{CO})_{8}\right)$ have been used.

The hardness of tungsten containing EBiD layer has been found to be in the range of 7.2 to $10.0 \mathrm{GPa}$ and for cobalt containing layers of 3.4 to $3.6 \mathrm{GPa}$. The measured hardness of the silicon substrate was $12.8 \mathrm{GPa}$, which agrees well with a value reported in literature $(12.1 \mathrm{GPa},[10])$.

Moreover, different fracture behaviours for these EBiD deposits have been observed. By examining the shape and the features of the imprints in the coatings after nanoindentation tests, it has been found that the tungsten containing layers have a brittle cracking behaviour, while the cobalt containing layers have a ductile fracture behaviour.

\section{References}

[1] A. N. Broers, W. W. Molzen, J. J. Cuomo, and N. D. Wittels. Electronbeam fabrication of $80 \AA ̊$ metal structures. Applied Physics Letters, 29(9):596-598, 1976.

[2] Robert W. Christy. Formation of thin polymer films by electron bombardment. Journal of Applied Physics, 31(9):1680-1683, 1960.

[3] F. Cicoira and P. Hoffmann. Focused electron-beam deposition of three dimensional free standing nanometer structures. Technical report, Institute of Applied Optics, DMT-IOA, EPFL, CH-1015 Lausanne, June 1999.

[4] Natalia Silvis Cividjian. Electron Beam Induced Nanometer Scale Deposition. PhD thesis, Technische Universiteit Delft, 2002.

[5] W. Ding, D. A. Dikin, X. Chen, R. D. Piner, R. S. Ruoff, E. Zussman, $\mathrm{X}$. Wang, and X. Li. Mechanics of hydrogenated amorphous carbon deposits from electron-beam-induced deposition of a paraffin precursor. Journal of Applied Physics, 98(1):014905, 2005. 
[6] A E Ennos. The sources of electron-induced contamination in kinetic vacuum systems. British Journal of Applied Physics, 5(1):27-31, 1954.

[7] M. Rudolph H. W. P. Koops, J. Kretz. Characterization and Application of Materials Grown by Electron-Beam-Induced Deposition. Jpn. J. Appl. Phys., 33(Part 1, 12B):7099-7107, 301994.

[8] P. Hoffmann, I. Utke, F.Cicoira et al. Focused electron beam induced deposition of gold and rhodium. Mat. Res. Soc. Symp. Proc., 624:171-177, 2000.

[9] Stephan Fahlbusch Ivo Utke, Vinzenz Friedli. Tensile Strengths of MetalContaining Joints Fabricated by Focused Electron Beam Induced Deposition. Advanced Engineering Materials, 8(3):137-140, 2006.

[10] Follstaedt D.M. Myers S.M. Petersen G.A. Knapp, J.A. Finite element modelling of nanoindentation measurements of crystalline and amorphous si. In Mat. Res. Soc. Symp. Proc., volume 649, 2001.

[11] H. W. P. Koops, C. Schossler, A. Kaya, and M. Weber. Conductive dots, wires, and supertips for field electron emitters produced by electron-beam induced deposition on samples having increased temperature. Volume 14, pages 4105-4109. AVS, 1996.

[12] W.C. Oliver and G.M. Pharr. An improved technique for determining hardness and elastic modulus using load and displacement sensing indentation experiments. Journal of Materials Research, 7(6):1554-1583, June 1992.

[13] N. Silvis-Cividjian, C.W. Hagen, L.H.A. Leunissen, and P. Kruit. The role of secondary electrons in electron-beam-induced-deposition spatial resolution. Microelectronic Engineering, 61-62:693-699, 2002.

[14] R. Lariviere Stewart. Insulating films formed under electron and ion bombardment. Phys. Rev., 45(7):488-490, Apr 1934.

[15] S. Fatikow T. Wich, S. Kray. Microrobot based testing of nanostructures inside an SEM. In Proceedings on the 10th International Conference on New Actuators, 2006.

[16] I. Utke, T. Bret, D. Laub, Ph. Buffat, L. Scandella and P. Hoffmann. Thermal effects during focused electron beam induced deposition of nanocomposite magnetic-cobalt-containing tips. Microelectron. Eng., 7374(1):553-558, 2004.

[17] I. Utke, F. Cicoira, G. Jaenchen, P. Hoffmann, and et al. Focused electron beam induced deposition of high resolution magnetic scanning probe tips. Mat. Res. Soc. Symp. Proc., 706:Z9.24.1-Z9.24.6, 2002.

[18] Sievers Wich, T. Assembly inside a Scanning Electron Microscope using Electron Beam induced Deposition. In Proceedings of 2006 IEEE/RSJ International Conference on Robots and Intelligent Systems, 92006.

[19] Chen X. Yan J. Karlsson A M. Zhao, M. Determination of uniaxial residual stress and mechanical properties by instrumented indentation. Acta Materialia, 54:2823-2832, 2006. 